\title{
Raman scattering of ferroelectric lead lanthanum titanate thin films grown on fused quartz by metalorganic chemical vapor deposition
}

\author{
Z.C. Feng ${ }^{\text {a,* }}$, J.H. Chen ${ }^{\text {a }}$, J. Zhao ${ }^{\text {b }}$, T.R. Yang ${ }^{c}$, A. Erbil ${ }^{\mathrm{d}}$ \\ ${ }^{a}$ Department of Electrical Engineering, Graduate Institute of Electro-Optical Engineering, National Taiwan University, Taipei 106, Taiwan, ROC \\ ${ }^{\mathrm{b}}$ College of Physics and Electronic Information, Tianjin Normal University, Tianjin 300074, PR China \\ ${ }^{\mathrm{c}}$ Department of Physics, National Taiwan Normal University, Taipei 117, Taiwan, ROC \\ ${ }^{\mathrm{d}}$ School of Physics, Georgia Institute of Technology, Atlanta, GA 30332, USA
}

Received 3 December 2003; received in revised form 9 December 2003; accepted 23 December 2003

Available online 6 May 2004

\begin{abstract}
Highly textured lead lanthanum titanate $\left(\mathrm{Pb}_{1-x} \mathrm{La}_{x}\right) \mathrm{TiO}_{3}$ (PLT) thin films have been grown on fused quartz substrates by metalorganic chemical deposition (MOCVD). A series of PLT with different $x$ between 0 and 0.32 were prepared and studied by Raman scattering. Raman spectra, measured at $300 \mathrm{~K}$ and $80 \mathrm{~K}$, showed the features from the PLT film and quartz substrate. By using a "difference Raman" technique, more PLT modes are shown. The variations of the PLT Raman modes with the La composition and the measurement temperature are studied, and related physical phenomena and problems are discussed.
\end{abstract}

(C) 2004 Elsevier Ltd and Techna Group S.r.l. All rights reserved.

Keywords: Lead lanthanum titanate; PLT; Raman scattering

\section{Introduction}

Lead lanthanum titanate $\left(\mathrm{Pb}_{1-x} \mathrm{La}_{x}\right) \mathrm{TiO}_{3}$ (PLT) is an important ferroelectric ceramic material that attracts much research interest currently [1-3]. It is also a necessary partner of lead lanthanum zircinate titanate (PLZT) [4-6] and lead lanthanum stannate zircinate titanate (PLZST) [7]. These PLT and related materials possess various novel properties, such as piezoelectricity, pyroelectricity, elasto-optic effect, linear or quadratic electro-optic effect, which are useful in applications for nonvolatile memory devices, detectors, sensors, and optical switches [1-8]. Efforts have been made to deposit PLT thin films on sapphire [9], MgO [10], and $\mathrm{Pt} / \mathrm{MgO}$ [11] substrates by rf magnetron sputtering technique, on Si by excimer laser ablation [12] and by metalorganic chemical vapor deposition (MOCVD) [13], on (lllll) sapphire by the sol-gel process [14], and recently on composite substrates of $\mathrm{ZrO}_{2} / \mathrm{SiO}_{2} / \mathrm{Si}$ by metalorganic deposi-

\footnotetext{
* Corresponding author. Tel.: +886-2-2363-5251x445; fax: +886-2-2367-7467.

E-mail address: zcfeng@cc.ee.ntu.edu.tw (Z.C. Feng).
}

tion (MOD) [1] and $\mathrm{Pt} / \mathrm{TiO}_{2} / \mathrm{SiO}_{2} / \mathrm{Si}$ by pulsed laser deposition $[2,3]$.

MOCVD is a useful technique for the deposition of various electronic and optoelectronic materials, and has been successfully applied by us to the growth of a series of ferroelectric thin films of $\mathrm{BaTiO}_{3}$ [15], $\mathrm{PbTiO}_{3}$ [16,17], and $\mathrm{PbZrTiO}_{3}(\mathrm{PZT})[18]$ on various substrates. We have also reported on the deposition and investigation of highly textured $\left(\mathrm{Pb}_{1-x} \mathrm{La}_{x}\right) \mathrm{TiO}_{3}$ (PLT) thin films on $\mathrm{Si}(100)$ by MOCVD [13]. These ferroelectric films have been characterized and investigated by X-ray diffraction (XRD) [16-18], scanning electron microscopy (SEM) [16], Rutherford backscattering spectroscopy (RBS) $[13,16,17]$ and Raman scattering $[13,17]$.

In this paper, we report on the deposition of a series of $\left(\mathrm{Pb}_{1-x} \mathrm{La}_{x}\right) \mathrm{TiO}_{3}(0<x<0.32)$ thin films on fused quartz by MOCVD and characterizations by Raman scattering.

\section{Experiment}

The MOCVD growth of PLT on fused quartz was similar to the case of PLT deposition on Si substrates [13]. Tetraethyl 
lead $\left[\mathrm{Pb}\left(\mathrm{C}_{2} \mathrm{H}_{5}\right)_{4}\right]$, titanium isopropoxide $\left[\mathrm{Ti}\left(\mathrm{OC}_{3} \mathrm{H}_{7}\right)_{4}\right]$, and lanthanum diketonate $[\mathrm{La} \text { (thd })_{3}$, thd $=\mathrm{C}_{11} \mathrm{H}_{19} \mathrm{O}_{2}$ ] were metalorganic sources for PLT. Argon was used as the carrier gas with the flow rates of 800,100 , and $200 \mathrm{sccm}$ for $\mathrm{Ti}-, \mathrm{Pb}-$, and La-sources, respectively. Temperatures for $\mathrm{Pb}-$ and La-sources were between $12-14^{\circ} \mathrm{C}$ and $120-140{ }^{\circ} \mathrm{C}$, respectively, while Ti-source temperature was in $28-31^{\circ} \mathrm{C}$. The substrate temperature was set at $550^{\circ} \mathrm{C}$. The reactor pressure was 70 Torr. An oxygen flow of $50 \mathrm{sccm}$ was used to enhance the pyrolysis, and more importantly, to eliminate the carbon incorporation in the film. The film thickness in this study ranging between 1500 and $3000 \AA$, and the La compositions ranging from 0 up to 0.32 were determined by RBS (not shown here).

All PLT thin films were first examined by XRD. Results are briefly described below. The $2 \theta$ diffraction patterns are obtained for all samples with peaks corresponding to $\left(\begin{array}{ll}0 & 01\end{array}\right)$, (1 00 ), ( $\left.\begin{array}{llll}1 & 0 & 1\end{array}\right),\left(\begin{array}{lll}1 & 1 & 0\end{array}\right),\left(\begin{array}{lll}1 & 1 & 1\end{array}\right),\left(\begin{array}{lll}0 & 0 & 2\end{array}\right)$, and (2 000$)$ crystalline planes, indicating that the films are polycrystalline in nature. The separation between $\left(\begin{array}{lll}0 & 1\end{array}\right)$ and $\left(\begin{array}{ll}10 & 0\end{array}\right)$ peaks decreases with increasing $x$. This demonstrates that the degree of tetragonality in these films decreases as the lanthanum concentration increases. This is consistent with the changes seen in PLT films grown on $\mathrm{MgO}$ by rf magnetron sputtering [11], and our MOCVD-grown PLT films on Si [13]. Detailed calculation of these PLT lattice constants $a$ along the $a$-axis parallel to the surface and $c$ along the $c$-axis normal to the surface for various La-concentrations as well as their tetragonality, $c / a$, will be given elsewhere together with XRD scan patterns.

Raman scattering measurements were performed in a near-backscattering geometry with the excitation source of $457.9 \mathrm{~nm}$ lines from an $\mathrm{Ar}^{+}$laser, using a triple spectrometer-optical multichannel analyzer (OMA) system $[13,17]$. Two gratings were used to achieve different scanning range and resolution ability.

\section{Results and discussion}

Figs. 1 and 2 show Raman spectra from five PLT/quartz samples with $x=0,0.054,0.167,0.212$, and 0.319 measured at $300 \mathrm{~K}$ and $80 \mathrm{~K}$, respectively, in the spectral range below $400 \mathrm{~cm}^{-1}$. Three major bands below $400 \mathrm{~cm}^{-1}$ characterize PLT modes [13]: the lowest frequency mode is a so-called soft mode, i.e. a transverse optical (TO) mode with the E symmetry $\mathrm{E}(1 \mathrm{TO})$ at $78 \mathrm{~cm}^{-1}$, the secondary $\mathrm{E}$ symmetry TO mode $\mathrm{E}(2 \mathrm{TO})$ is located at $197 \mathrm{~cm}^{-1}$, and a silent mode at $283 \mathrm{~cm}^{-1}$. These three major modes of $\mathrm{E}(1 \mathrm{TO}), \mathrm{E}(2 \mathrm{TO})$, and silent can be seen in all four samples, although they are weak for the $x=0.319$ PLT film, and also almost unrecognized for the $x=0.212$ PLT film, indicating the poor quality of this sample. An additional $\mathrm{A}_{1}(1 \mathrm{TO})$ mode at $150 \mathrm{~cm}^{-1}$ is seen for PLT with $x<$ 0.167 and sharper at $80 \mathrm{~K}$ than $300 \mathrm{~K}$. The $\mathrm{E}(1 \mathrm{LO})$ mode at $125 \mathrm{~cm}^{-1}$ is observed at $80 \mathrm{~K}$ measurements only. Also, a

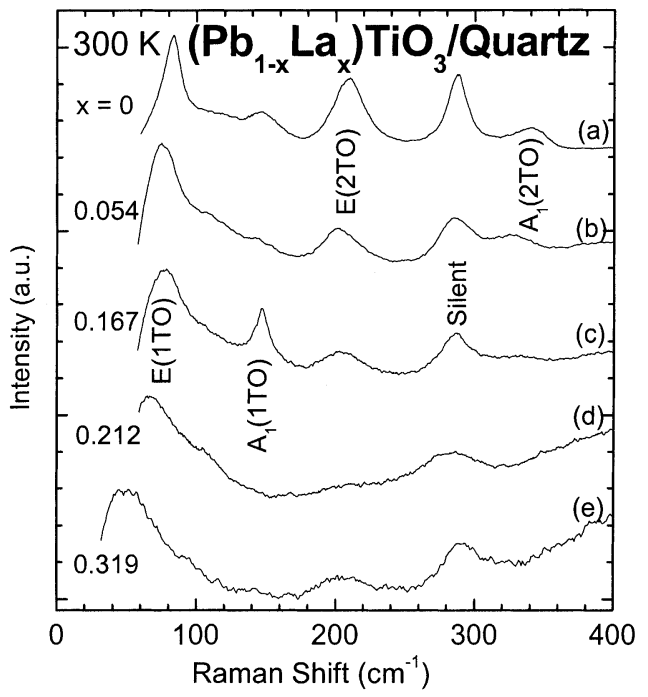

Fig. 1. Raman spectra taken at $300 \mathrm{~K}$ under excitation of $457.9 \mathrm{~nm}$ and $100 \mathrm{~mW}$, showing the major PLT phonon bands below $400 \mathrm{~cm}^{-1}$, from MOCVD-grown $\left(\mathrm{Pb}_{1-x} \mathrm{La}_{x}\right) \mathrm{TiO}_{3}$ /quartz for $x$ values of: (a) 0, (b) 0.054, (c) 0.167 , (d) 0.212 , and (e) 319 .

mode near $330-340 \mathrm{~cm}^{-1}$ is seen and assigned to $\mathrm{A}_{1}(2 \mathrm{TO})$ [14,19].

We have previously used the difference Raman scattering technique to treat Raman spectra of $\mathrm{PbTiO}_{3}$ thin films grown on substrates of $\mathrm{KTaO}_{3}$ and quartz by MOCVD [17], by way of which, Raman modes from the ferroelectric film can be recognized clearly. We are now employing this method to further study the PLZ films grown on quartz. Figs. 3 and 4 show the Raman spectra for a typical $\left(\mathrm{Pb}_{1-x} \mathrm{La}_{x}\right) \mathrm{TiO}_{3}$ $(x=0.10)$ thin film grown on quartz by MOCVD, its bare

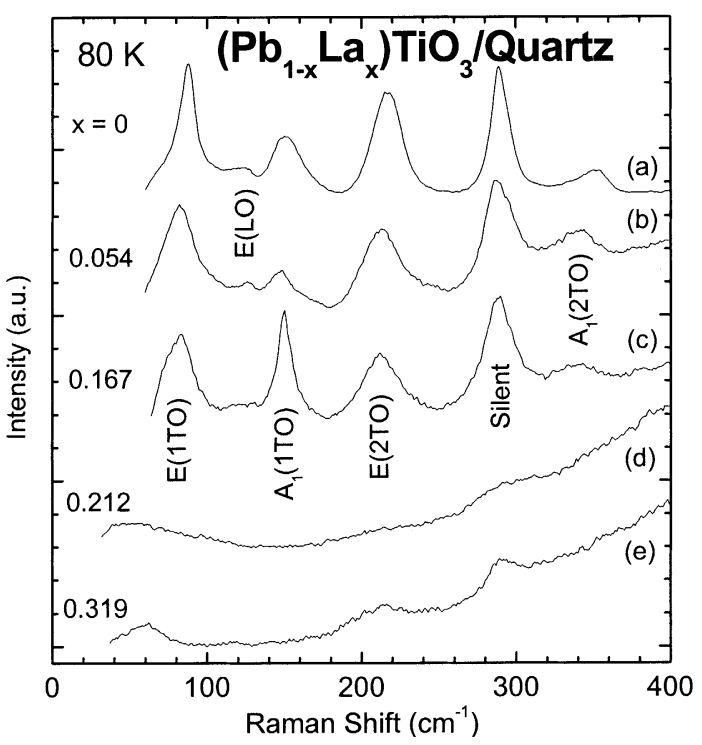

Fig. 2. Raman spectra taken at $80 \mathrm{~K}$ under excitation of $457.9 \mathrm{~nm}$ and $100 \mathrm{~mW}$, showing the major PLT phonon bands below $400 \mathrm{~cm}^{-1}$, from $\left(\mathrm{Pb}_{1-x} \mathrm{La}_{x}\right) \mathrm{TiO}_{3} /$ quartz for $x$ values of: (a) 0, (b) 0.054 , (c) 0.167 , (d) 0.212 , and (e) 0.319 . 


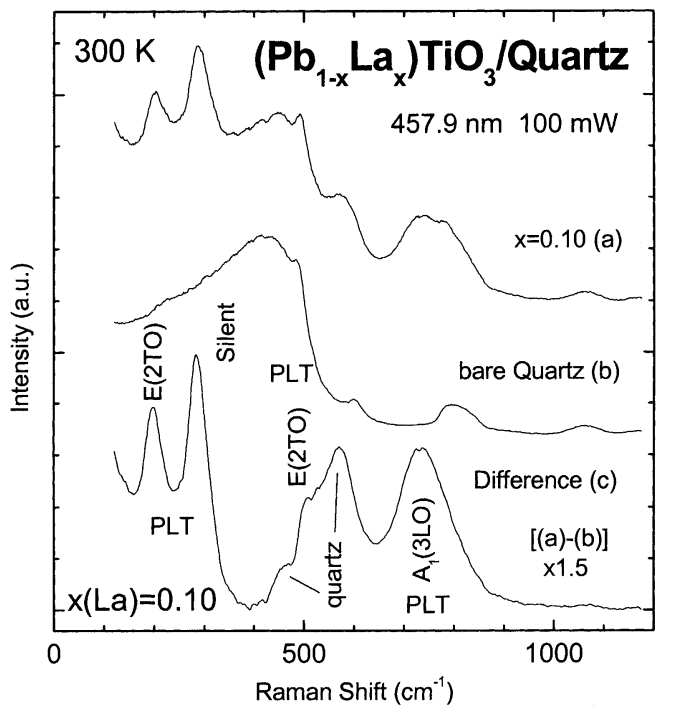

Fig. 3. Raman spectra $(300 \mathrm{~K})$ under excitation of $4579 \AA$ and $100 \mathrm{~mW}$, from (a) $x=0.10\left(\mathrm{~Pb}_{1-x} \mathrm{La}_{x}\right) \mathrm{TiO}_{3}$ quartz, (b) bare quartz region, and (c) difference of $(a-b)$.

substrate and the difference between them in the frequency range of $100-1200 \mathrm{~cm}^{-1}$ and measured between 300 and $80 \mathrm{~K}$, respectively. The secondary $\mathrm{E}(2 \mathrm{TO})$ at $197 \mathrm{~cm}^{-1}$ and the silent mode at $283 \mathrm{~cm}^{-1}$ are seen directly from the Raman spectrum without subtracting the contributions from substrate (Figs. 3a and 4a). They are superposed upon the low frequency side of a broad Raman band, peaked near $400 \mathrm{~cm}^{-1}$, from quartz, and this is same also for the soft mode when we changed a grating to scan (not shown here). Two weak bands located at 123 and $148 \mathrm{~cm}^{-1}$, respectively, can bee seen from the LT difference spectrum, Fig. 4c, which

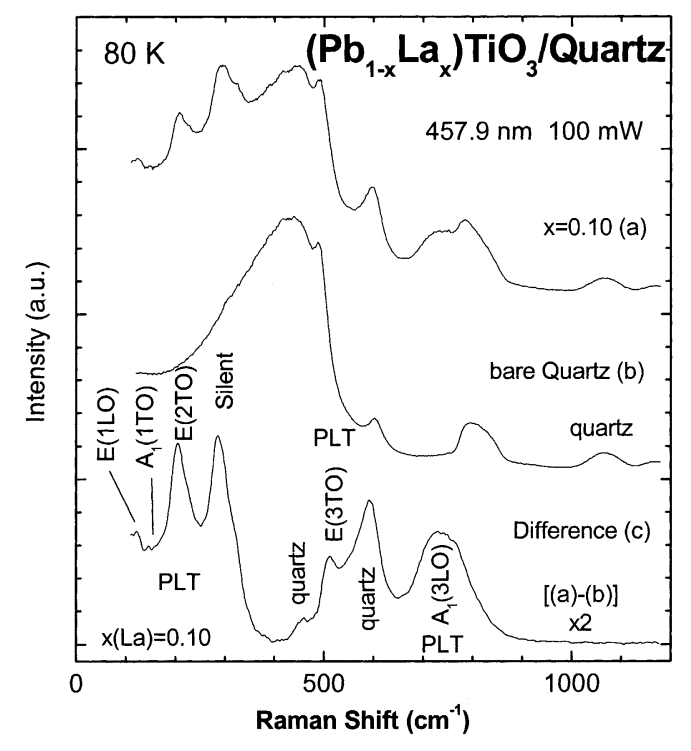

Fig. 4. Raman spectra $(80 \mathrm{~K})$ under excitation of $4579 \AA$ and $100 \mathrm{~mW}$, from (a) $x=0.10\left(\mathrm{~Pb}_{1-x} \mathrm{La}_{x}\right) \mathrm{TiO}$ quartz, (b) bare quartz region, and (c) difference of $(a-b)$. had been observed for powder PLT [19] and can be assigned as $\mathrm{E}(1 \mathrm{LO})$ and $\mathrm{A}_{1}(1 \mathrm{TO})$, respectively, following the assignments for $\mathrm{PbTiO}_{3}$ [20].

Beyond $400 \mathrm{~cm}^{-1}$, the spectrum of PLT/quartz (Figs. 3a and 4a) consists of contributions from both PLT and quartz, which can not be distinguished simply. In comparison with the spectrum from bare quartz (Figs. $3 b$ and $4 b$ ), it is seen that the Raman feature at $1060 \mathrm{~cm}^{-1}$ from quartz does not appear from the difference spectra, Figs. $3 \mathrm{c}$ and $4 \mathrm{c}$. The quartz mode at $800 \mathrm{~cm}^{-1}$ does not appear in Figs. $3 \mathrm{c}$ and $4 \mathrm{c}$ also, leaving a broad band between 650 and $950 \mathrm{~cm}^{-1}$ and with the peak at about $730 \mathrm{~cm}^{-1}$. This band is recognized to be a PLT longitudinal optical (LO) phonon mode with an $\mathrm{A}_{1}$ symmetry and assigned as A(3LO) from PLT.

Between 400 and $650 \mathrm{~cm}^{-1}$, there exist a small bump slightly below $500 \mathrm{~cm}^{-1}$ and band at $600 \mathrm{~cm}^{-1}$ which are from the quartz substrate. In the difference spectrum of Fig. 4c, these two features still exist. But a third band exhibits clearly between these two modes located at $515 \mathrm{~cm}^{-1}$ which is assigned as E(3TO) from PLT film. At the RT difference spectrum, Fig. 3c, this E(3TO) mode and a quartz mode in its lower frequency side appear not so sharp as they appear at LT spectrum, Fig. 4c. LT ( $80 \mathrm{~K})$ measurements can produce better results.

The dependence of the mode frequencies on $x$ for our PLT/quartz samples can be obtained from above Raman spectra. The data are consistent with that for PLT/Si $\left(\begin{array}{lll}1 & 0\end{array}\right)$ [13] and that from Katiyar [14]. All modes except for the so-called "silent mode" show some systematic changes as a function of the composition and temperature. The "silent mode", which is not Raman or infrared active [21], exhibits a unique compositional and temperature dependence where the position $\left(287-288 \mathrm{~cm}^{-1}\right)$ almost does not vary with either the La composition or temperature. Its appearance in Raman spectra might be due to the disorder in samples.

The frequency of the $\mathrm{E}(\mathrm{TO})$ soft mode decreases in wavenumber with an increase of $x$ for both $300 \mathrm{~K}$ and $80 \mathrm{~K}$, which is consistent with the results of $\mathrm{PbTiO}_{3}$ thin films [17] and PLT/Si [13].

\section{Conclusion}

In summary, we have successfully grown lead lanthanum titanate (PLT) thin films on fused quartz substrates by metalorganic chemical vapor deposition. Films with the La composition less than 0.32 were characterized by $\mathrm{X}$-ray diffraction, Raman spectroscopy, and Rutherford backscattering. X-ray diffraction showed the polycrystalline nature of these films. Raman spectra were studied and compared with that from our MOCVD-grown PLT on Si(100). Difference Raman technique was used to exhibit better the features from PLT films by subtracting the contributions from quartz substrates. More features from PLT films can be recognized or distinguished at low temperature $(80 \mathrm{~K})$ measurements. The composition and temperature dependent 
behaviors of the Raman modes of PLT with $0<x<0.32$ are obtained. Some empirical trends can be seen that the TO-like and LO-like modes decrease and increase, respectively, with increasing $x$, and that the silent mode does not depend on $x$ in the range studied. The success of the growth of the complex PLT ferroelectric films on the widely available quartz substrates by MOCVD may enhance further the development and application of ferroelectric thin film materials.

\section{Acknowledgements}

We are grateful to Profs. S. Perkowitz and C.C. Yang for their support and help in this work.

\section{References}

[1] Z.T. Song, H.L.W. Chan, Y.P. Ding, N. Chong, C.L. Choy, J. Appl. Phys. 91 (6) (2002) 3779-3784.

[2] M. Labardi, C. Polop, V. Likodimos, L. Pardi, M. Allegrini, E. Vasco, C. Zaldo, Appl. Phys. Lett. 83 (10) (2003) 2028-2030.

[3] K.B. Han, C.H. Jeon, H.S. Jhon, S.Y. Lee, Mater. Sci. Semicond. Process. 5 (2-3) (2003) 249-252.

[4] H.-J. Zhao, T.-L. Ren, N.-X. Zhang, R.-Z. Zuo, X.-H. Wang, L.-T. Liu, Z.-J. Li, Z.-L. Gui, L.-T. Li, Mater. Sci. Eng. B99 (1-3) (2003) 195-198.
[5] M. Kakada, K. Ohashi, M. Lebedev, J. Akedo, Jpn. J. Appl. Phys. 42 (Part 1, 9B) (2003) 5960-5962.

[6] K. Tsuzuki, T. Kobayashi, J. Appl. Phys. 42 (Part 1, 9B) (2003) 6027-6032.

[7] M. Chen, X. Yao, L. Zhang, Ceram. Int. 28 (2) (2002) 201-207.

[8] R. Ramesh, S. Aggarwal, O. Auciello, Mater. Sci. Eng. R32 (6) (2001) 191-236.

[9] H. Adachi, T. Mitsuyu, O. Yamazaki, K. Wasa, J. Appl. Phys. 60 (2) (1986) 736-741.

[10] R. Takayama, Y. Tomita, K. ujima, I. Ueda, J. Appl. Phys. 60 (8) (1986) 2914-2919.

[11] K. Iijima, R. Takayama, Y. Tomita, I. Ueda, J. Appl. Phys. 63 (12) (1988) 5868-5872.

[12] G.A. Petersen, L.C. Zou, W.M. van Buren, L.L. Boyer, J.R. McNeil, in: E.R. Myers, A.I. Kingon (Eds.), Ferroelectric Thin Films, Mater. Res. Soc. Symp. Proc. 200 (1991) 127-132.

[13] Z.C. Feng, B.S. Kwak, A. Erbil, L.A. Boatner, Appl. Phys. Lett. 64 (18) (1994) 2350-2352.

[14] P.S. Dobal, S.B. Majumder, S. Bhaskar, R.S. Katiyar, J. Raman Spectrosc. 30 (7) (1999) 567-572.

[15] B.S. Kwak, K. Zhang, E.P. Boyd, A. Erbil, B.J. Wilkens, J. Appl. Phys. 69 (2) (1991) 767-772.

[16] B.S. Kwak, A. Erbil, B.J. Wilkens, J.D. Budai, M.F. Chisholm, L.A Boatner, Phys. Rev. Lett. 68 (25) (1992) 3733-3736.

[17] Z.C. Feng, B.S. Kwak, A. Erbil, L.A. Boatner, Appl. Phys. Lett. 62 (4) (1992) 349-351.

[18] W. Braun, B.S. Kwak, A. Erbil, J.D. Budai, L.A. Boatner, B.J. Wilkins, Appl. Phys. Lett. 63 (4) (1993) 467-469.

[19] G. Burns, B.A. Scott, Solid State Commun. 13 (3) (1973) 417-420.

[20] N.E. Tornberg, C.H. Perry, J. Chem. Phys. 53 (10) (1970) 29462955.

[21] G. Burns, B.A. Scott, Phys. Rev. B7 (7) (1973) 3088-3101. 